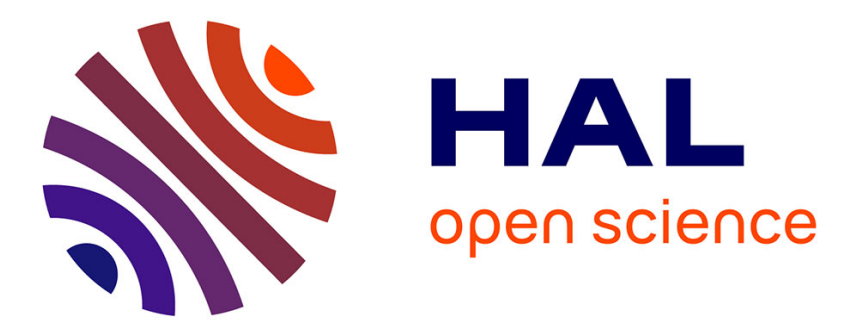

\title{
Squeezing Flow of Suspensions: Flow Regime Evaluation from Energy Approach
}

Patrice Estellé, Yannick Mélinge, Christophe Lanos, Arnaud Perrot

\section{To cite this version:}

Patrice Estellé, Yannick Mélinge, Christophe Lanos, Arnaud Perrot. Squeezing Flow of Suspensions: Flow Regime Evaluation from Energy Approach. THE XV INTERNATIONAL CONGRESS ON RHEOLOGY: The Society of Rheology 80th Annual Meeting, Aug 2008, Monterey, United States. pp.818-820, 10.1063/1.2964858 . hal-00672916

\section{HAL Id: hal-00672916 https://hal.science/hal-00672916}

Submitted on 28 Jan 2014

HAL is a multi-disciplinary open access archive for the deposit and dissemination of scientific research documents, whether they are published or not. The documents may come from teaching and research institutions in France or abroad, or from public or private research centers.
L'archive ouverte pluridisciplinaire HAL, est destinée au dépôt et à la diffusion de documents scientifiques de niveau recherche, publiés ou non, émanant des établissements d'enseignement et de recherche français ou étrangers, des laboratoires publics ou privés. 


\title{
Squeezing Flow of Suspensions: Flow Regime Evaluation from Energy Approach
}

\author{
Patrice Estellé ${ }^{\mathrm{a}}$, Yannick Mélinge ${ }^{\mathrm{a}}$, Christophe Lanos $^{\mathrm{a}}$, Arnaud Perrot ${ }^{\mathrm{b}}$ \\ ${ }^{a}$ UEB-LGCGM Equipe Matériaux et Thermo-Rhéologie - IUT-INSA Rennes, 3 rue du Clos Courtel, BP 90422, \\ Rennes cedex 7, France \\ ${ }^{b}$ Centre de Recherche de St Maudé, Université Bretagne Sud, 56321 Lorient cedex, France
}

\begin{abstract}
The squeezing flow geometry is here used to investigate the properties of concentrated suspensions. The suspensions consist in idealized system of smooth hard spheres dispersed in a yield stress colloidal gel. During the squeezing action, the material structure evolves with energy variation due to particle displacement and interaction. The goal of our study is to evaluate the energy evolution from a Fourier analysis as a function of solid volume fraction and compression velocity.
\end{abstract}

Keywords: Suspensions, particles, squeeze flow, energy distribution

PACS: 83

\section{INTRODUCTION}

Industrial and natural materials mainly consist in particles (fiber, solid or soft elements) in a suspended fluid. So, such suspensions are largely investigated due to their practical interest and application. Squeeze flow is now a commonly used technique in rheometry, as shown the recent review of [1]. Such geometry is presently used to investigate the flowing behavior of particles in suspension from an energetic point of view. Actually, following the size and volume fraction of particles, the suspension behaves as a homogeneous yield stress fluid to a lubricated or granular media [2]. During the squeezing, the material structure may evolve with energy variation, which is due to particle displacement, interaction and collision. This is the aim here to evaluate such a phenomenon from an idealized system of spheres dispersed in a yield stress material. We focus in particular on the influence of particle concentration and compression speed of squeezing movement.

\section{MATERIAL AND EXPERIMENTS}

The suspensions consist of hard glass spherical particles (1 $\mathrm{mm}$ in diameter) dispersed in a colloidal gel. Gel composition and density, particles properties as well suspension preparation are detailed in [3]. It is worth noting that rheometric experiments have shown that the gel behaves as a yield stress fluid, which can be well modeled with an Herschel-Bulkley constitutive equation [3]. The volume fraction of the suspensions investigated ranges from $48.5 \%$ to packing value.

The suspensions are squeezed out between two plates $(50 \mathrm{~mm}$ in diameter) with roughened surfaces to avoid slippage. Squeezing experiments were carried out with a texture analyzer [4] in both constant area geometry and compression speed. The initial gap between the plates is $15 \mathrm{~mm}$ before the squeezing action. Squeeze force and sample gap are recorded during tests for two fixed compression speeds: 0.1 and $8 \mathrm{~mm} / \mathrm{s}$. Typical squeeze flow curves are depicted in figure 1. This clearly shows the test beginning at low sample gap with a compaction phase, then the suspensions flow as the squeeze force increase. As expected also, the sample gap at high compression force depends on particle concentration. It is also shown three distinct behaviors for the suspensions. The lower concentrated suspension behaves as the suspended fluid. The three highly concentrated suspensions behave similarly. The transition is obtained for the suspension with dense random packing value [5]. 


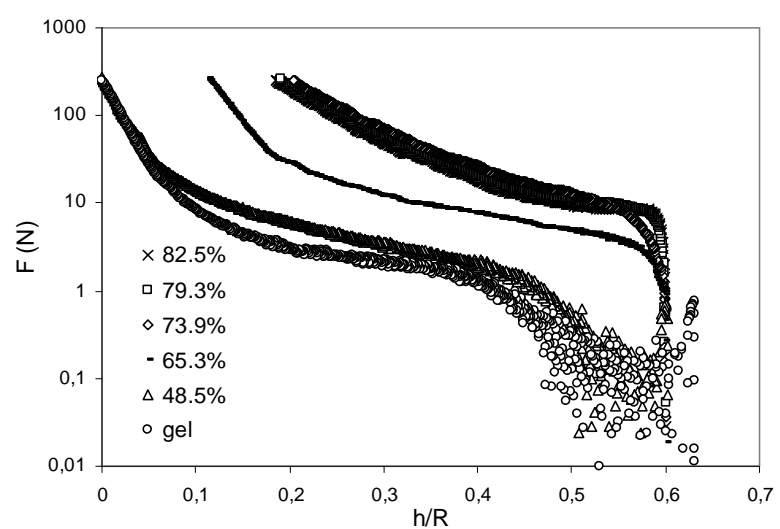

FIGURE 1. Squeeze force versus sample gap plate radius ratio - influence of particle concentration for a $8 \mathrm{~mm} / \mathrm{s}$ compression speed.

\section{THEORY AND EXPERIMENTAL RESULTS}

It is assumed that the squeeze force, denoted $F$, is decomposed $\mathrm{n}$ successive windowed signals of duration $\mathrm{T}$. Each of these signals is a linear combination of fluctuating and average components, respectively denote $\bar{F}$ and $F^{\prime}$ (see eq. 1). Moreover, we consider the average component as a linear function of time.

$$
F(t)=\bar{F}(t)+F^{\prime}(t) \text { with } \bar{F}^{\prime}=\frac{1}{T} \int_{0}^{T} F^{\prime} d t=0 \text { and } \omega=2 \pi / T \text { (1) }
$$

In the following, the power spectrum density, PSD, is used as an indicator of energy variation in the flowing suspension. PSD is defined as the magnitude modulus of the Fast Fourier Transform of $F^{\prime}$, as shown equation (2). This allows the energy variation to be evaluated in the frequency domain.

$$
P S D=\left\|F F T\left(F^{\prime}\right)\right\| \text { with } F F T\left(F^{\prime}\right)=\int_{0}^{T} F^{\prime}(t) . e^{J \omega t} d t(2)
$$

Such an analysis requires first an appropriate choice of T. Comparison of different values of this parameter was done in [3]. It was shown that a 256 points value is optimal in terms of frequency domain and PSD values and shape. Moreover, it was demonstrated that the fluctuating force component is very sensitive to particle interaction and collision. Finally, energy contribution linked to the drive motor and compression speed effect was shown to be predominant at high frequency value, with energy peaks at 40,80 and $120 \mathrm{~Hz}$ [3]. This allows distinguishing the energy contribution due to the instrument and the one linked to squeezed material, as shown figure 2 . As the compression force increases, the PSD value increases and is enlarged, with complex spectrum at low frequency.

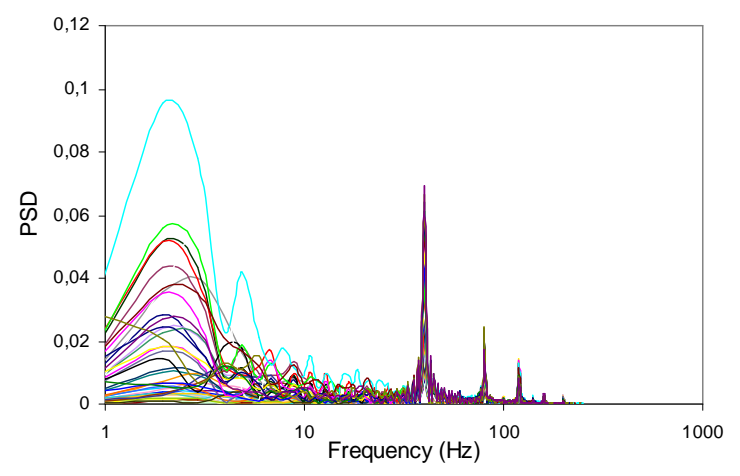

FIGURE 2. Evolution of PSD among frequency for the $48.5 \%$ suspension when plates are close. Color line corresponds to PSD of windowed fluctuating force signal. 
To make clearer our analysis, an average value of PSD, $\mathrm{PSD}_{\mathrm{a}}$, was considered to evaluate the influence of particle concentration and compression speed. It corresponds to the area of PSD curve for the frequency range divided by the half of sampling rate, $f_{\max }$. Its evolution is expressed against an average sample height value, $h_{a}$.

$$
P S D_{a}=\frac{1}{f_{\max }} \int_{0}^{f_{\max }} P S D(f) d f(3)
$$

In figure 3, we report the results obtained with the suspensions, varying the particle concentration and the compression speed. As a result, the following remarks can be made.

For both compression speeds, the $\mathrm{PSD}_{\mathrm{a}}$ increases as the sample gap decreases. This was expected as sample gap reduction induces particle movement and interaction.

The energy dissipation is quite similar for the higher concentrated suspensions. Energy dissipates by the lower concentrated suspension is very similar to the one of gel because this suspension is very dilute. The lower concentrated are the suspensions, the higher is the final sample gap.

It should be noted that energy dissipation may be similar for the different suspensions, but it was obtained for various sample gap.

The global evolution of $\mathrm{PSD}_{\mathrm{a}}$ value does not depend on compression velocity. However, the effect of compression velocity is the following. The $\mathrm{PSD}_{\mathrm{a}}$ is lower with $0.1 \mathrm{~mm} / \mathrm{s}$ compression speed. With this velocity, particles move slowly, from rearrangement and lubricated contact rather than with collision and forced contact as obtained with high compression speed.
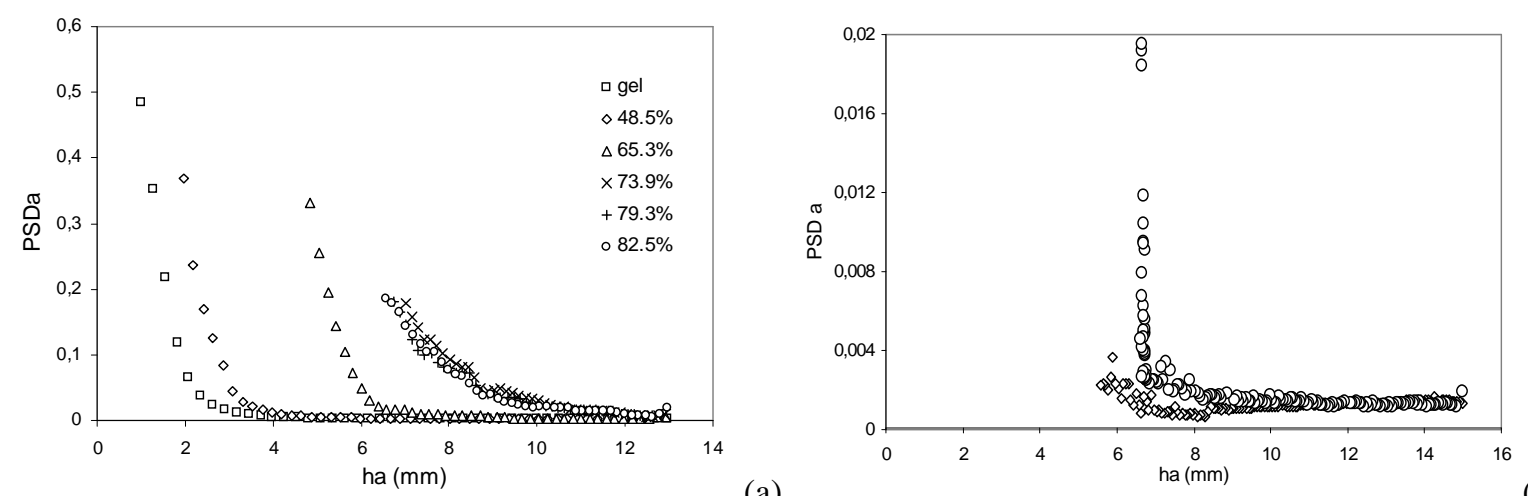

(a)

FIGURE 3. Energy evolution with PSDa indicator against average sample height. (a) influence of particle concentration at $8 \mathrm{~mm} / \mathrm{s}$ compression speed ; (b) influence of particle concentration at $0.1 \mathrm{~mm} / \mathrm{s}$ compression speed

\section{ACKNOWLEDGMENTS}

This work is supported by the French National Agency of Research (ANR) under the project Physepat (05-NT05443247).

\section{REFERENCES}

1. J. Engmann et al., J. Non-Newt. Fluid Mech. 132, 1-27 (2005).

2. P. Coussot and C. Ancey, Phys. Rev. E59, 4445-4457 (1999).

3. P. Estellé et al., Granular Matter 10, 81-87 (2008).

4. P. Estellé et al., Measurement 39, 771-777 (2006).

5. C. Servais et al., J. Food Eng., 51, 201-208 (2002). 